\title{
Prolactin inhibition in dams during lactation programs for overweight and leptin resistance in adult offspring
}

\author{
Isabela Teixeira Bonomo, Patricia Cristina Lisboa, Analaura Ribeiro Pereira, Magna Cottini \\ Fonseca Passos ${ }^{1}$ and Egberto Gaspar de Moura \\ Departmento de Ciências Fisiológicas, Instituto de Biologia Roberto Alcantara Gomes, Universidade do Estado do Rio de Janeiro, Av. 28 de setembro, 87 Rio de \\ Janeiro, RJ, 20551-030, Brazil \\ ${ }^{1}$ Departmenté Nutrição Aplicada, Instituto de Nutrição, Universidade do Estado do Rio de Janeiro, Rio de Janeiro, Brazil \\ (Requests for offprints should be addressed to P C Lisboa; Email: pclisboa@uerj.br)
}

\begin{abstract}
Maternal malnutrition during lactation reduces prolactin (PRL) and milk production, alters milk composition, and programs the body weight of the offspring. Our study aimed to evaluate the long-term effects of maternal hypoprolactinemia at the end of lactation on food ingestion, body weight, amount of retroperitoneal white adipose tissue (RPWAT), leptinemia, and anorectic leptin effect in the adult offspring. Lactating rats were treated with bromocriptine (BRO), a PRL inhibitor, $1 \mathrm{mg}$ twice a day, or saline $(\mathrm{C}-$ control) for the last 3 days of lactation. The body weight and food intake were monitored, and after sacrifice at 180 days, the RPWAT was weighted. In a second experiment, the anorectic leptin effect was tested on 180-day-old animals. Adult offspring whose
\end{abstract}

mothers were BRO-treated showed higher body weight $(10 \%)$, higher amount of RPWAT $(2 \cdot 3$ times), higher total body fat $(+39 \%)$, and hyperleptinemia (2.9 times) when compared with $\mathrm{C}$, although food intake did not alter. After injection of leptin, the food ingestion at 2, 4 and $6 \mathrm{~h}$ was unaffected in BRO animals, confirming a resistance to the anorectic effect of leptin. Since the maternal PRL inhibition during lactation programs, a higher body weight with no alteration of food ingestion, we suggest a hypometabolic state. The leptin anorectic resistance can be due to the hyperleptinemia. We suggest that PRL changes during lactation can regulate body weight during adulthood.

Journal of Endocrinology (2007) 192, 339-344

\section{Introduction}

Our group has shown that adverse situations during lactation, such as malnutrition and hormonal changes, could permanently affect the nutritional and hormonal status of the progeny (Passos et al. 2000, 2002, 2004, Cravo et al. 2002, Teixeira et al. 2002, 2003, Vicente et al. 2004, Lins et al. 2005). This association has been denominated as metabolic imprinting or programing, which is defined as a biological phenomenon that determines relationship between physical and chemical stimuli in early life and future functional status (Lucas 1994, Waterland \& Garza 1999, Barker 2003, Moura \& Passos 2005). Barker et al. (1993) has associated low birth weight with diseases related to the metabolic syndrome (diabetes, obesity, and hypertension) during adulthood.

The body-weight modulation is performed by many factors, including hormones, such as leptin. Leptin is a hormone secreted by adipose tissue, which reduces the food intake and increases the energy expenditure, maintaining the body-weight homeostasis (Zhang et al. 1994, Friedman \& Halaas 1998). Maternal energy malnutrition during lactation programs overweight in the adult offspring, without change in food consumption (Passos et al. 2000). Those animals presented a leptin resistance to their anorexigenic effect (Passos et al. 2004).

During lactation, in rats, malnutrition causes hypoprolactinemia (Lisboa et al. 2006), explaining the failure in milk synthesis and changes in their macronutrient, iodine, and thyroid hormone content (Passos et al. 2000, 2001a,b). Previously, we reported that the milk production suppression through the inhibition of prolactin (PRL) synthesis with administration of an agonist of dopaminergic receptor type 2, bromocriptine (BRO), causes malnutrition in neonatal pups and changes the transfer of leptin through the milk (Bonomo et al. 2005).

Therefore, in this work, we investigated the consequences of maternal hypoprolactinemia during lactation upon body weight, food intake, leptin, and leptin anorectic action in the adult life of the offspring.

\section{Material and Methods}

Three-month-old Wistar rats were maintained in a room under a $7 \mathrm{~h}$ light: $19 \mathrm{~h}$ darkness cycle and controlled temperature $\left(23 / 24^{\circ} \mathrm{C}\right)$. Virgin female rats were caged with one male rat at a ratio of $2: 1$. After mating, each female was 
placed in an individual cage with water and food available ad libitum until parturition. The use of the animals was according to the Animal Care and Use Committee of the Biology Institute of the State University of Rio de Janeiro, which based their analysis on the principles described in the Guide for the Care and Use of Laboratory Animals (Bayne 1996).

After birth, excess pups were removed, so that only six male pups were kept per dam, because it has been shown that this procedure maximizes lactation performance (Fishbeck \& Rasmussen 1987).

Twelve lactating rats were separated into the following groups: BRO - treated with $1 \mathrm{mg}$ bromo- $\boldsymbol{\alpha}$-ergocriptine (BRO; Novartis, SP, Brazil), twice a day, for the last 3 days of lactation before death and $\mathrm{C}-$ control group, which received saline treatment for the same time (Bonomo et al. 2005). We tested several days of PRL inhibition and 3 days was the maximum period that permitted the pups' survival through to adulthood (data not shown). Table 1 shows the body weight of the pups before and during maternal BRO treatment.

After weaning (21 days of lactation), three pups of each dams' group had their body weight and relative food intake (g/100 g BW) monitored every 4 days until 180 days, when the rats were killed by decapitation. Trunk blood was collected and the retroperitoneal white adipose tissue (RPWAT) was dissected out and immediately weighed.

\section{Body fat determination}

The rats were eviscerated and the carcass was weighed, autoclaved for $1 \mathrm{~h}$, and homogenized on distilled water $(1: 1$; Leshner \& Litwin 1972). The homogenate was stored at $-20{ }^{\circ} \mathrm{C}$ for analysis. Three grams of homogenates were used for determining the fat mass gravimetrically (Stansbie 1976, Toste et al. 2006). The samples were hydrolyzed on a shaking water bath at $70{ }^{\circ} \mathrm{C}$ for $2 \mathrm{~h}$ with $30 \% \mathrm{KOH}$ and ethanol. The total fatty acids and free cholesterol were removed by washing three times with petroleum ether. After drying overnight in a vacuum, all tubes were weighed and data were expressed as grams of fat per $100 \mathrm{~g}$ carcass.

\section{Leptin anorectic effect test}

Peptide Recombinant mouse leptin (PeproTech, Rocky Hill, NJ, USA) was dissolved in saline $(0.9 \% \mathrm{wt} / \mathrm{vol})$ and

Table 1 Body weight of pups during maternal $\mathrm{BRO}$ or saline treatment. Values are given as the means \pm S.E.M.

\begin{tabular}{|c|c|c|}
\hline & C (g) & BRO (g) \\
\hline \multicolumn{3}{|c|}{ Days of lactation } \\
\hline $19^{\prime}$ & $50 \cdot 4 \pm 1 \cdot 2$ & $48 \cdot 0 \pm 0 \cdot 8$ \\
\hline 20 & $53 \cdot 1 \pm 1 \cdot 1$ & $50 \cdot 0 \pm 0 \cdot 7^{*}$ \\
\hline 21 & $55 \cdot 5 \pm 1 \cdot 3$ & $51 \cdot 2 \pm 0 \cdot 6^{*}$ \\
\hline
\end{tabular}

injected as a bolus at a dose of $0.5 \mathrm{mg} / \mathrm{kg}$ body weight intraperitoneally (Martin et al. 2000, Passos et al. 2004).

Feeding study $\mathrm{C}$ and BRO adult (180 days old) offspring were divided into the following groups: leptin (Clep and BROLep) or saline (Csal and BROsal). All groups were fooddeprived for $24 \mathrm{~h}$ with free access to water before the test. After injection, the rats were returned individually to their cages and provided with the standard diet. Food intake was measured by weighing the food, 2,4 , and $6 \mathrm{~h}$ after leptin or saline injections. In order to check the effectiveness of the acute leptin injection, we measured leptinemia after $2 \mathrm{~h}$ and $24 \mathrm{~h}$ in both groups.

\section{Serum leptin}

Blood samples of 180-days old C and BRO offspring were centrifuged and serum was stored at $-20{ }^{\circ} \mathrm{C}$ until assayed. Leptin was determined by RIA kit (Linco Research, St Charles, MO, USA). This kit has an assay sensitivity of $0.5 \mathrm{ng} / \mathrm{ml}$ and a range of detection from 0.5 to $50 \mathrm{ng} / \mathrm{ml}$. All measures were done in one assay. The intra-assay variation was $6 \cdot 9 \%$.

\section{Statistical analysis}

Data are reported as means \pm s.E.M. Two-way ANOVA and Newman-Keuls multiple comparison were used to analyze food intake in response to the leptin acute administration, and the Student's $t$-test to analyze the other experimental observations, with significance level set at $P<0 \cdot 05$.

\section{Results}

During maternal BRO treatment, pups presented a significant low body weight gain (day 2, 6\%; day 3,8\%), as demonstrated in Table 1 .

The body weight of offspring whose mothers were injected with BRO for the last 3 days of lactation was significantly higher than the controls from day 133 until 180 days, reaching about $10 \%$ of overweight $(P<0 \cdot 05 ; \mathrm{C}, 397 \cdot 4 \pm 8 \cdot 9$ vs BRO, $438 \cdot 2 \pm 20 \cdot 8$; Fig. 1). However, these rats did not show changes in relative food intake since weaning until adult life (C, $4 \cdot 4 \pm 0 \cdot 3$ vs BRO, $4 \cdot 0 \pm 0 \cdot 7$; Fig. 2 ).

We also detected on 180 days-old BRO group, a higher amount of RPWAT $(2 \cdot 3$ times, $P<0 \cdot 05 ; \mathrm{C}, 14 \cdot 7 \pm 2 \cdot 8$ vs BRO, 33.3 $\pm 2 \cdot 6$; Fig. 3$)$ and total body fat $(+39 \%, P<0 \cdot 05$; C, $7 \cdot 4 \pm 0 \cdot 5$ vs BRO, $10 \cdot 3 \pm 0 \cdot 7$; Fig. 4 ), confirming that the overweight is due, at least in part, to an increase in adiposity.

The adult rats of BRO-treated dams presented hyperleptinemia (2.9 times, $P<0 \cdot 05$; C, $5 \cdot 8 \pm 1 \cdot 3$ vs BRO, 17.0 $\pm 1 \cdot 7$; Fig. 5). To check this high leptin serum levels in BRO group, we performed an anorectic test of the leptin effect. The test effectiveness of the anorectic effect of leptin is showed by the data of $\mathrm{C}$ group, where leptin injection inhibited more than 


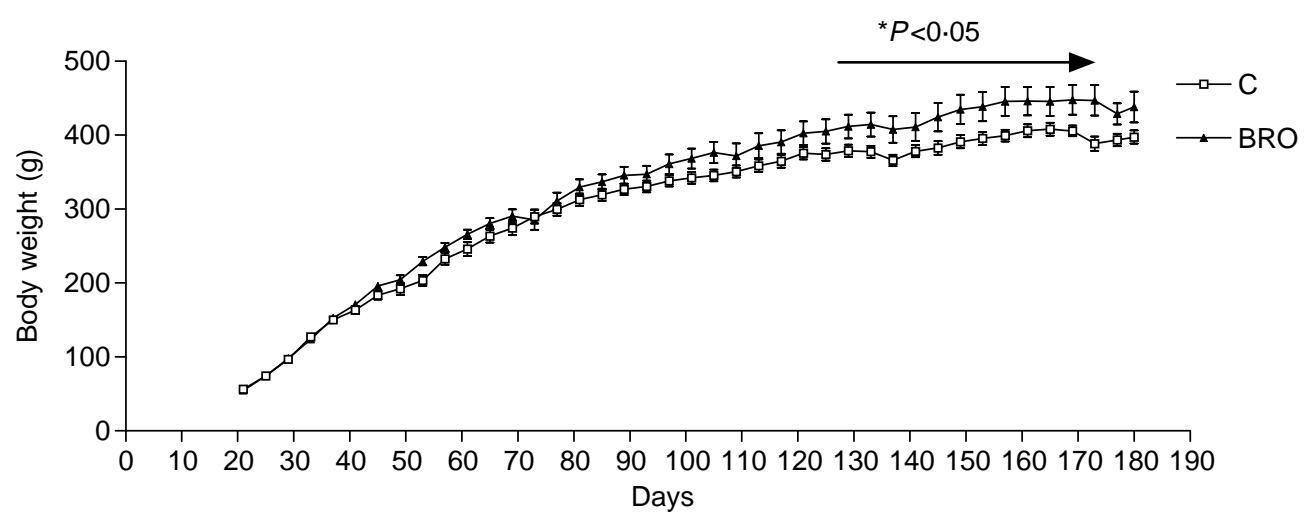

Figure 1 Body-weight evolution, from weaning to adulthood, of offspring whose mothers were BRO-treated (BRO) or saline-treated (C) during lactation. Values are given as the mean \pm S.E.M. $n=18$ animals/group, ${ }^{*} P<0 \cdot 05$.

$50 \%$ of the food intake when compared with group Csal, in all the three periods studied (Fig. 6A, Table 2). However, leptininjected BRO group showed unaffected food intake after 2, 4, and $6 \mathrm{~h}$ (Fig. 6B, Table 2), which demonstrates a resistance to the leptin anorexigenic action. We also measured leptinemia after $2 \mathrm{~h}$ of acute saline or leptin administration and after $24 \mathrm{~h}$ in both groups, as shown in Table 3. Clep and BROlep presented high serum leptin after $2 \mathrm{~h}(+1 \cdot 24$ times and $+100 \%$ respectively) and unchanged levels after $24 \mathrm{~h}$.

\section{Discussion}

We showed previously that hypoprolactinemia at the end of lactation causes malnutrition (Bonomo et al. 2005), because there was a marked decrease in milk production. Other authors showed a different kind of programming by energy malnutrition during lactation (Waterland \& Garza 1999, Godfrey \& Barker 2000, Vickers et al. 2000, Passos et al. 2000, 2002, 2004, Breier et al. 2001, Teixeira et al. 2002, Vicente et al. 2004). Here, we showed that maternal hypoprolactinemia at the end of lactation caused overweight, higher visceral fat, hyperleptinemia, and hypothalamic leptin resistance in their adult offspring.
The higher body weight with normal food intake detected in BRO adult rats is similar to our previous data in adult animals whose mothers were submitted to energy restriction during lactation (Passos et al. 2002, Teixeira et al. 2002). In the present work, we showed that the overweight developed by the adult offspring of BRO-treated dams was due, at least partially, to a higher amount of central adiposity.

In obese individuals, higher leptin levels do not produce the expected satiety and increase in energetic expenditure. This unexpected leptin effect is explained through leptin resistance, caused by downregulation of their hypothalamic receptors (Considine et al. 1996, Martin et al. 2000), by a reduced blood-brain barrier transport (Burguera et al. 2000, Banks 2001) or by an impairment of the intracellular transduction pathway (Widdowson 1997, Wilson et al. 1999, Ahima \& Flier 2000, Jéquier 2002).

Concerning the leptin anorectic test in adult BRO offspring, since we did not detect a decrease in food consumption after leptin acute injection, as observed for the adult control rats, it is reasonable to believe that adult BRO rats did have a hypothalamic leptin resistance. The leptin resistance observed in BRO adult rats may be explained by their hyperleptinemia. These programmed rats also presented higher serum leptin levels at weaning (Bonomo et al. 2005), similar to the changes observed in leptinemia of pups whose

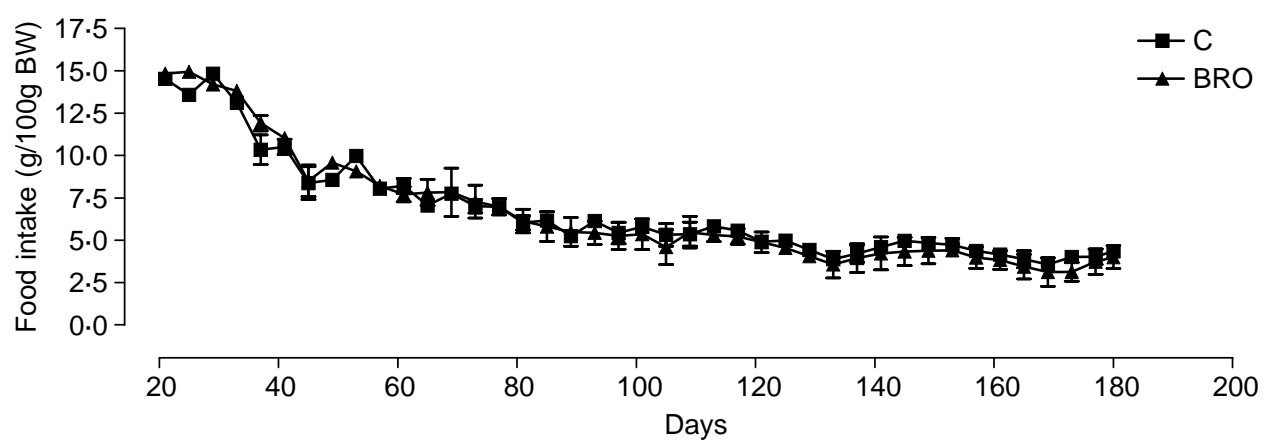

Figure 2 Food intake evolution, from weaning to adulthood, of offspring whose mothers were BRO-treated (BRO) or saline-treated (C) during lactation. Values are given as the means \pm s.E.M. $n=18$ animals/group. 


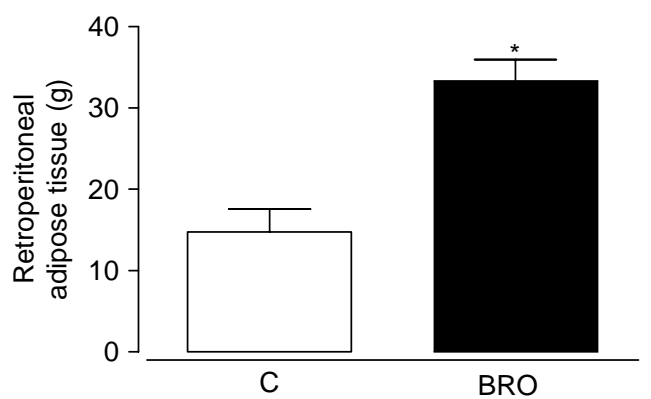

Figure 3 Amount of retroperitoneal white adipose tissue (RPWAT) of adult offspring whose mothers were BRO-treated (black bars) or saline-treated (white bars) during lactation. Values are given as the mean \pm s.E.M. $n=10$ animals/group, ${ }^{*} P<0 \cdot 001$.

mothers were malnourished during lactation (Teixeira et al. 2002). When the pups of energy-malnourished mothers become adults, they also presented leptin resistance (Passos et al. 2004). In the same way, other models of neonatal leptin imprinting (Cravo et al. 2002, Lins et al. 2005, Toste et al. 2006) are associated with leptin resistance. It seems that in the present model, higher neonatal leptinemia also imprints for leptin resistance at adulthood. Our data support the hypothesis of a central role of leptin on the body-weight control mechanisms imprinted at the beginning of life, especially on lactation.

We detected an $8 \%$ decrement on body weight of BRO pups at 21 days-old, corroborating our previous findings (Bonomo et al 2005), which characterize neonatal malnutrition. This early malnutrition may be the imprinting factor for adult overweight, as demonstrated by other authors (Waterland \& Garza 1999, Godfrey \& Barker 2000, Vickers et al. 2000, Passos et al. 2000, 2002, 2004, Breier et al. 2001, Teixeira et al. 2002, Vicente et al. 2004). Thus, we believe that maternal hypoprolactinemia early in a pup's life plays the relevant role for the nutritional imprinting phenomena detected in our study. Our hypothesis is supported by the fact that milk presents large amounts of PRL, which is probably transferred by the milk and absorbed by the immature newborn gastrointestinal tract (Ellis \& Picciano

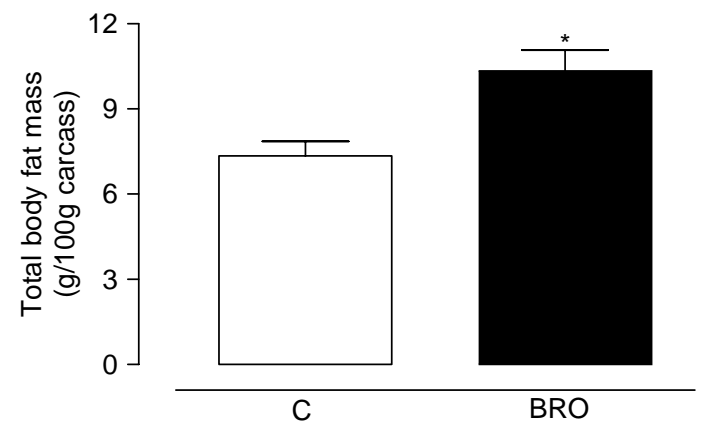

Figure 4 Total body fat mass of adult offspring whose mothers were BRO-treated (black bars) or saline-treated (white bars) during lactation. Values are given as the mean \pm S.E.M. $n=10$ animals/ group, ${ }^{*} P<0 \cdot 007$.

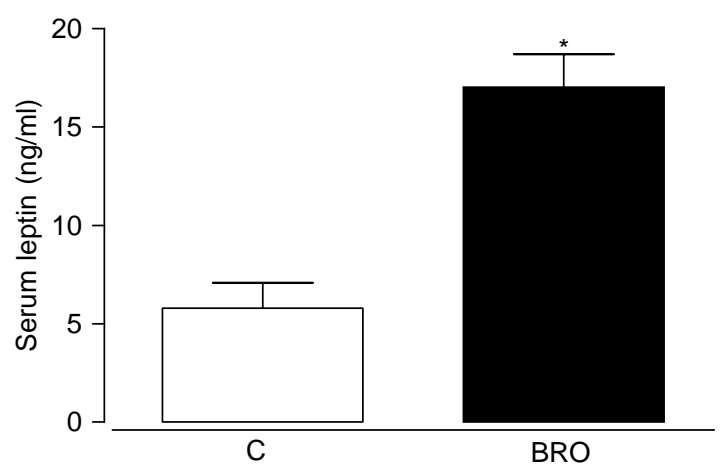

Figure 5 Serum leptin levels of adult offspring whose mothers were BRO-treated (black bars) or saline-treated (white bars) during lactation. Values are given as the mean \pm S.E.M. $n=10$ animals/ group, ${ }^{*} P<0 \cdot 01$.

1995, Ben-Jonathan et al 2006). However, the function of this milk secreted PRL on the developing offspring is unknown.

The events that could link low maternal PRL imprinting with the higher body weight of the offspring were based on the fact that $\mathrm{BRO}$ offspring received higher leptin transfer through the milk (Bonomo et al. 2005) and that leptin administration to pups or to dams are related with the same kind of body weight programming (Lins et al. 2005, Toste et al. 2006).
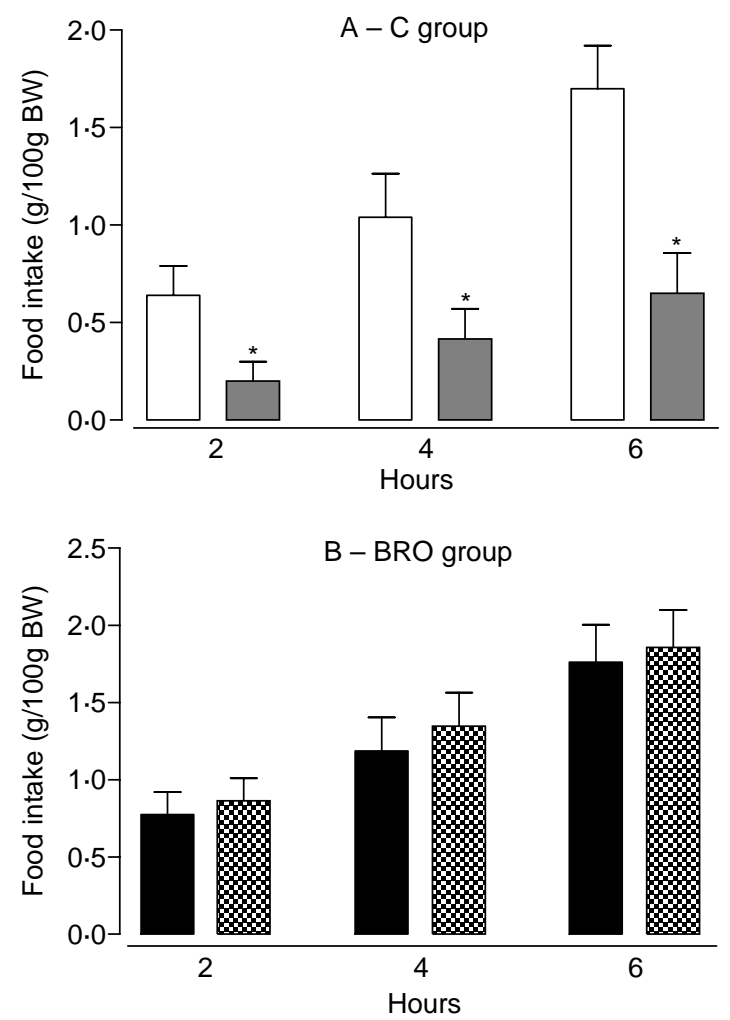

Figure 6 (A) Leptin anorectic effect of $C$ adult offspring: Csal (white bar) and Clep (gray bars). (B) Leptin anorectic effect of BRO adult offspring: BROsal (black bars) and BROlep (checkered bars). Values are given as the mean \pm s.E.M. $n=8$ animals/group $* P<0 \cdot 05$.

www.endocrinology-journals.org 
Table 2 Food intake (g) in leptin anorectic test of BRO and C adult offspring. Values are given as the means \pm s.E.M.

\begin{tabular}{|c|c|c|c|}
\hline & $2 \mathrm{~h}$ & $4 \mathrm{~h}$ & $6 \mathrm{~h}$ \\
\hline C sal & $0 \cdot 6 \pm 0 \cdot 2$ & $1 \cdot 0 \pm 0 \cdot 2$ & $1 \cdot 7 \pm 0 \cdot 2$ \\
\hline C lep & $0 \cdot 2 \pm 0 \cdot 1 *$ & $0 \cdot 4 \pm 0 \cdot 2^{*}$ & $0 \cdot 7 \pm 0 \cdot 2^{*}$ \\
\hline BRO sal & $0 \cdot 8 \pm 0 \cdot 1$ & $1 \cdot 2 \pm 0 \cdot 2$ & $1 \cdot 8 \pm 0 \cdot 2$ \\
\hline BRO lep & $0 \cdot 9 \pm 0 \cdot 1$ & $1 \cdot 4 \pm 0 \cdot 2$ & $1 \cdot 9 \pm 0 \cdot 2$ \\
\hline
\end{tabular}

$n=8$ animals/group, $* P<0 \cdot 05$.

Table 3 Leptinemia $(\mathrm{ng} / \mathrm{ml}) / 2 \mathrm{~h}$ leptin anorectic test of BRO and C adult offspring. Values are given as the means \pm S.E.M.

\begin{tabular}{|c|c|c|}
\hline & $2 \mathrm{~h}$ & $24 \mathrm{~h}$ \\
\hline C sal & $5 \cdot 8 \pm 1 \cdot 3$ & $5 \cdot 7 \pm 1 \cdot 4$ \\
\hline C lep & $13 \cdot 0 \pm 2 \cdot 8^{*}$ & $8 \cdot 0 \pm 1 \cdot 8$ \\
\hline BRO sal & $17 \cdot 0 \pm 1 \cdot 7$ & $17 \cdot 4 \pm 1 \cdot 6$ \\
\hline BRO lep & $34 \cdot 0 \pm 3 \cdot 3^{*}$ & $22 \cdot 3 \pm 2 \cdot 1$ \\
\hline
\end{tabular}

$n=5$ animals/group, $* P<0 \cdot 05$.

Another important issue is related to the model of PRL blockade. Here, we only used BRO with the aim of PRL inhibition, but it is difficult to distinguish the hypoprolactinemia effect and a possible direct BRO effect on the pups, as well as the short-term and moderate (8\%) undernutrition, much more higher in the maternal malnourished models ( $20 \%$ for a longer period). $\mathrm{BRO}$ is a specific dopamine type 2 receptor agonist, mainly found in the pituitary gland (Ben-Jonathan \& Hnasko 2001). Therefore, even if BRO is transferred through the milk to the pups, its putative effect is over pups' PRL itself. Then, we believe that maternal PRL inhibition by BRO is the main imprinting factor. Further studies are being carried out in order to test a possible direct $\mathrm{BRO}$ effect in pups.

Finally, our data make evident the crucial role of PRL, even when it is blocked for a short period at the end of lactation, as an important factor that programs body weight regulation and adiposity, suggesting the importance of the PRL effect on milk transfer of other possible imprinting factors, such as leptin.

\section{Acknowledgements}

Research was supported by CNPq, CAPES, and FAPERJ. The authors are grateful to Ms Lauciene Andrade and $\mathrm{Mr}$ Carlos Roberto for their technical assistance. The authors declare that there is no conflict of interest that would prejudice the impartiality of this scientific work.

\section{References}

Ahima RS \& Flier JS 2000 Leptin. Annual Reviews Physiology 11 413-437. Banks WA 2001 Leptin transport across the blood-brain barrier: implications for the cause and treatment of obesity. Current Pharmaceutical Design 7 125-133.
Barker DJP 2003 The developmental origins of adult disease. European Journal of Epidemiology 18 733-736.

Barker DJP, Hales CN, Fall CH, Osmond C, Phippes K \& Clark PM 1993 Type 2 (non-insulin-dependent) diabetes mellitus, hypertension and hyperlipidaemia (syndrome X): relation to reduced fetal growth. Diabetologia 36 62-67.

Bayne K 1996 Revised Guide for the Care and Use of Laboratory Animals available. American Physiology Society 39 208-211.

Ben-Jonathan N, Hugo ER, Brandebourg TD \& LaPensee CR 2006 Focus on prolactin as a metabolic hormone. Trends in Endocrinology and Metabolism 17 110-116.

Bonomo IT, Lisboa PC, Passos MCF, Pazos-Moura CC, Reis AM \& Moura EG 2005 Prolactin inhibition in lactating rats changes leptin transfer through the milk. Hormone and Metabolic Research 37 220-225.

Breier BH, Vickers MH, Ikenasio KY, Chan KY \& Wong WPS 2001 Fetal programming of appetite and obesity. Molecular and Cellular Endocrinology $18573-79$.

Burguera B, Couce ME, Curran GL, Jensen MD, Lloyd RV, Cleary MP \& Poduslo JF 2000 Obesity is associated with a decreased leptin transport across the blood-brain barrier in rats. Diabetes 49 1219-1223.

Considine RV, Sinha MK, Heiman ML, Kriauciunas A, Stephens TW, Nyce MR, Ohannesian JP, Marco CC, Mckee LJ, Bauer TL et al. 1996 Serum immunoreactive-leptin concentrations in normal weight and obese humans. New England Journal of Medicine 334 292-295.

Cravo CO, Teixeira CV, Passos MC, Dutra SC, Moura EG \& Ramos C 2002 Leptin treatment during the neonatal period is associated with higher food intake and adult body weight in rats. Hormone and Metabolic Research 34 400-405.

Ellis LA \& Picciano MF 1995 Bioactive and immunoreactive prolactin variants in human milk. Endocrinology 136 2711-2720.

Fishbeck KL \& Rasmussen KM 1987 Effect of repeated cycles on maternal nutritional status, lactational performance and litter growth in ad libitum-fed and chronically food-restricted rats. Journal of Nutrition 117 1967-1975.

Friedman JM \& Halaas JL 1998 Leptin and the regulation of body weight in mammals. Nature 395 763-770.

Godfrey KM \& Barker DJ 2000 Fetal nutrition and adult disease. American Journal of Clinical Nutrition 71 1344S-1352S.

Jéquier E 2002 Leptin signaling, adiposity, and energy balance. Annals of the New York Academy Sciences 967 379-388.

Leshner AL \& Litwin VA 1972 A simple method for carcass analysis. Physiology and Behavior 9 282-289.

Lins MC, Moura EG, Lisboa PC, Bonomo IT \& Passos MCF 2005 Effects of maternal leptin treatment during lactation on the body weight and leptin resistance of adult offspring. Regulatory Peptides 127 197-202.

Lisboa PC, Passos MCF, Dutra SCP, Bonomo IT, Denolato ATA, Reis AM \& Moura EG 2006 Leptin and prolactin, but not corticosterone, modulate body weight and thyroid function in protein-malnourished lactating rats. Hormone and Metabolic Research 38 295-299.

Lucas A 1994 Role of nutritional programming in determining adult morbidity. Archives of Disease in Childhood 71 288-290.

Martin RL, Perez E, He YJ, Dawson R \& Millard WJ 2000 Leptin resistance is associated with hypothalamic leptin receptor mRNA and protein down regulation. Metabolism 49 1479-1484.

Moura EG \& Passos MCF 2005 Neonatal programming of body weight regulation and energetic metabolism. Bioscience Report 25 251-269.

Passos MCF, Ramos CF \& Moura EG 2000 Short and long term effects of malnutrition in rats during lactation on the body weight of offspring. Nutrition Research 20 1603-1612.

Passos MCF, Ramos CF, Dutra SCP \& Moura EG 2001a Transfer of iodine through the milk in protein-restricted lactating rats. Journal of Nutritional Biochemestry 12 300-303.

Passos MCF, Ramos CF, Mouço T \& Moura EG $2001 b$ Increase of T3 secreted through the milk in protein restricted lactating rats. Nutrition Research 21 917-924.

Passos MCF, Ramos CF, Dutra SCP, Mouço T \& Moura EG 2002 Long-term effects of malnutrition during lactation on the thyroid function of offspring. Hormone and Metabolic Research 34 40-43. 
Passos MCF, Vicente LL, Lisboa PC \& Moura EG 2004 Absence of anoretic effect to acute peripheral leptin treatment in adult animals whose mothers were malnourished during lactation. Hormone and Metabolic Research 36 625-629.

Stansbie D 1976 Regulation of the human pyruvate dehydrogenase complex. Clinical and Science Molecular Medicine 51 445-452.

Teixeira CV, Passos MCF, Ramos CF, Dutra SCP \& Moura EG 2002 Leptin serum concentration, food intake and body weight in rats whose mothers were exposed to malnutrition during lactation. Journal of Nutritional Biochemeistry 13 493-498.

Teixeira CV, Ramos CDF, Mouco T, Passos MCF \& Moura EG 2003 Leptin injection during lactation alters thyroid function in adult rats. Hormone and Metabolic Research 35 367-371.

Toste FP, de Moura EG, Lisboa PC, Fagundes AT, de Oliveira E \& Passos MC 2006 Neonatal leptin treatment programmes leptin hypothalamic resistance and intermediary metabolic parameters in adult rats. British Journal of Nutrition 95 830-837 In press.

Vicente LL, Moura EG, Lisboa PC, Costa AMA, Amadeu T, Mandarimde-Lacerda CA \& Passos MCF 2004 Malnutrition during lactation is associated with higher expression of leptin receptor in pituitary of the adult offspring. Nutrition 20 924-928.
Vickers MH, Breier BH, Cutfield WS, Hofman PL \& Gluckman PD 2000 Fetal origins of hyperphagia, obesity and hypertension and its postnatal amplification by hypercaloric nutrition. American Journal of Physiology 279 E83-E87.

Waterland RA \& Garza C 1999 Potential mechanisms of metabolic imprinting that lead to chronic disease. American Journal of Clinical Nutrition 69179 197.

Widdowson PS 1997 Obesity in diabetes and the impact of leptin. Diabetes Reviews International 6 2-5.

Wilson BD, Ollman MM \& Barsh GS 1999 The role of agouti-related protein in regulating body weight. Molecular Medicine Today 5 250-256.

Zhang Y, Proença R, Maffei M, Barone M, Leopold L \& Friedman JM 1994 Positional cloning of the mouse obese gene and its human homologue. Nature 372 425-432.

Received in final form 31 October 2006

Accepted 3 November 2006

Made available online as an Accepted Preprint

15 November 2006 